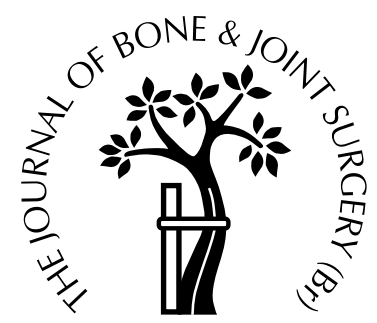

\title{
The long-term outcome after central cord syndrome
}

\author{
A STUDY OF THE NATURAL HISTORY \\ Martyn L. Newey, Pradeep K. Sen, Robert D. Fraser \\ From the University of Adelaide, Australia
}

$\mathbf{W}$ e studied 32 patients with central cord syndrome who were managed conservatively. Six were under 50 years of age (group 1), 16 between 50 and 70 years (group 2) and ten over 70 years (group 3).

At the time of discharge all patients in group 1 could walk independently and had good bladder control compared with $11(69 \%)$ and $14(88 \%)$ in group 2 and four $(40 \%)$ and two $(20 \%)$ in group 3 , respectively.

At follow-up after a mean of 8.6 years (4 to 15), ten patients had died leaving 22 in the study. All those in group 1 were alive, could walk independently and had bladder control. In group 2, 13 were alive of whom ten $(77 \%)$ could walk independently and nine (69\%) had bladder control. In group 3 only three were alive of whom only one was independent and none had bladder control.

Function at discharge as measured by the ASIA motor scoring system was usually maintained or improved at follow-up, but patients over 70 years of age at injury did poorly.

J Bone Joint Surg [Br] 2000;82-B:851-5.

Received 28 January 1999; Accepted after revision 25 June 1999

Central cord syndrome typically presents in an elderly patient with pre-existing cervical spondylosis. The mechanism of injury involves hyperextension with pinching of the spinal cord between a thickened ligamentum flavum and a protruding anterior osteophyte or disc. An associated fracture of a cervical vertebra is uncommon. The typical neurological deficit is symmetrical incomplete quadriplegia affecting the upper more than the lower limbs; sensory impairment is variable and urinary retention common.

M. L. Newey, BSc, FRCS Ed (Orth), Neuro-Orthopaedic Spinal Fellow R. D. Fraser, MD, FRACS, Professor and Head of Spinal Unit

Department of Orthopaedics and Trauma, University of Adelaide, Bice Building Level 4, Royal Adelaide Hospital, North Terrace, Adelaide, South Australia 5000.

P. K. Sen, MS Orth, FRACS, Orthopaedic Surgeon

Hampstead Spinal Rehabilitation Centre, 207-255 Hampstead Road, Northfield, South Australia 5085.

Correspondence should be sent to Professor R. D. Fraser.

(C)2000 British Editorial Society of Bone and Joint Surgery 0301-620X/00/49866 \$2.00

VOL. 82-B, No. 6, AUGUST 2000
Since the original article by Schneider, Cherry and Pantek $^{1}$ several authors ${ }^{2-6}$ have described the outcome after central cord syndrome. Although these patients are usually managed conservatively some authors have advocated surgical treatment in selected cases. ${ }^{7-9}$ None of these studies, however, is prospective or randomised. There is evidence that the outcome is better in younger patients, ${ }^{5,10}$ although the natural history is not yet clearly defined. Our aim in this retrospective study was to determine the longer-term outcome in these patients.

\section{Patients and Methods}

Between 1983 and 1995, 254 patients had been admitted with injuries to the cervical spinal cord of which 42 $(16.5 \%)$ had symptoms consistent with central cord syndrome. They were included in this study and their case notes analysed. In all, motor deficit was more pronounced in the upper limbs and there was variable sensory loss. Radiological investigation indicated extrinsic compression of the cord in ten who subsequently had surgical decompression, leaving 32 who were managed conservatively.

There were 26 men and six women with a mean age of 60.8 years (19 to 83 ). Penrod et al ${ }^{10}$ suggested that the outcome is better in patients under 50 years of age, and we therefore grouped patients by age. Group 1 consisted of six patients with a mean age of 29.3 years (19 to 47), group 2 of 16 with a mean age of 62.8 years (50 to 70) and group 3 of ten patients with a mean age of 76.6 years ( 71 to 83 ). All were managed by bed rest, either with or without traction, and were mobilised with a neck brace before undergoing rehabilitation. All except four received steroids during their initial management.

At admission and discharge we recorded the motor scores for the upper and lower limbs using the American Spinal Injury Association (ASIA) system, mobility and

Table I. Mechanism of injury for the three groups (see text)

\begin{tabular}{lrrr}
\hline Group & $\mathbf{1}$ & $\mathbf{2}$ & $\mathbf{3}$ \\
\hline Fall & 2 & 9 & 6 \\
Road-traffic accident & 1 & 5 & 4 \\
Sport & 3 & 1 & 0 \\
Assault & 0 & 1 & 0 \\
Total & 6 & 16 & 10 \\
\hline
\end{tabular}


Table II. Radiological findings in the three groups

\begin{tabular}{llrr}
\hline Group & $\mathbf{1}$ & $\mathbf{2}$ & $\mathbf{3}$ \\
\hline Degenerative changes & 3 & 16 & 10 \\
Stenosis & 3 & 9 & 6 \\
Fracture & 4 & 7 & 2 \\
\hline
\end{tabular}

Table III. The mean number of days in hospital and undergoing rehabilitation in the three groups

\begin{tabular}{lcc}
\hline & Hospital stay & Rehabilitation \\
\hline Group 1 & 24 & 68 \\
Group 2 & 26 & 115 \\
Group 3 & 26 & 100 \\
\hline
\end{tabular}

bladder function. The ASIA scores were determined by the addition of segmental values for upper and lower limbs as previously described. ${ }^{10}$

Walking was considered to be independent if the patient required no assistance other than that provided by splints.

For the longer follow-up all surviving patients completed a short-form general health questionnaire (SF36) and had a clinical review including a functional independence measure (FIM), and a further ASIA motor score. For those who had died, information was sought from relatives and care workers. The mean time from injury to final follow-up was 8.6 years (2 to 15$)$.

\section{Results}

Table I shows the mechanism of injury for the three age groups. Of the patients aged over 50 years the plain radiographs showed a fracture in less than half; in all except one this involved the posterior column (Table II). In patients under 50 years of age all the fractures were of the anterior column.

Patients over 70 years of age (group 3) showed poorer ASIA scores at admission and discharge for both the upper and lower limbs (Fig. 1). All patients under 50 years of age (group 1) were able to walk and had good bladder function at discharge, whereas only 11 (69\%) of those aged from 50 to 70 years (group 2) and four (40\%) of those over 70 years of age (group 3) could walk independently, with 14 (88\%) of group 2 and two (20\%) of group 3 having bladder control. The number of days in hospital was similar for all groups but patients under 50 years of age spent less time undergoing rehabilitation (Table III).

Longer-term review. At the time of follow-up, ten patients had died leaving 22 available for review. The survivors included all patients in group 1, 13 in group 2 and three in group 3. The mean follow-up time from injury for the survivors was 8.6 years (4 to 15 ).

SF36 profiles for the general Australian population were obtained from the Australian Bureau of Statistics. ${ }^{11}$ There were no significant differences in profiles standardised for age and gender between groups 1 and 2 (Fig. 2). Only two of the three patients in group 3 completed the form successfully.

Patients in group 1 scored better on the FIM than those in group 2 except in communication and cognition skills. Patients in group 3 scored poorly (Fig. 3).

Motor power continued to improve after discharge from hospital (Fig. 4). In the upper limb, the distal roots were more severely affected at the time of injury than the proximal roots, but this difference was less noticeable at the final review (Fig. 5). In groups 1 and 2, the mean individual motor score for roots $\mathrm{C} 5$ to $\mathrm{C} 7$ was over 9 at review whereas for roots $\mathrm{C} 8$ and $\mathrm{T} 1$ it was between 8 and 9 . In group 3, only roots C5 and C6 had a mean score greater than 9; the remainder scored 8 or less.

At review, all patients in group 1 could walk and had good bladder control compared with ten $(77 \%)$ and nine (69\%), respectively, in group 2 . Only one of the three patients in group 3 could walk independently and none had bladder control. Compared with their function at discharge, two patients in group 2 had regained the ability to walk independently and a further two, one each from groups 2 and 3, had lost independence. Two patients from group 2 and one from group 3 had developed urinary incontinence.

Five patients in group 2 and all of group 3 were unable to perform fine motor tasks such as undoing buttons, as reflected by their ASIA scores (particularly the T1 root values) and their FIM assessment. Five patients in group 1 and four in group 2 also had difficulty with such tasks and hand function was restricted by fatigue even when motor

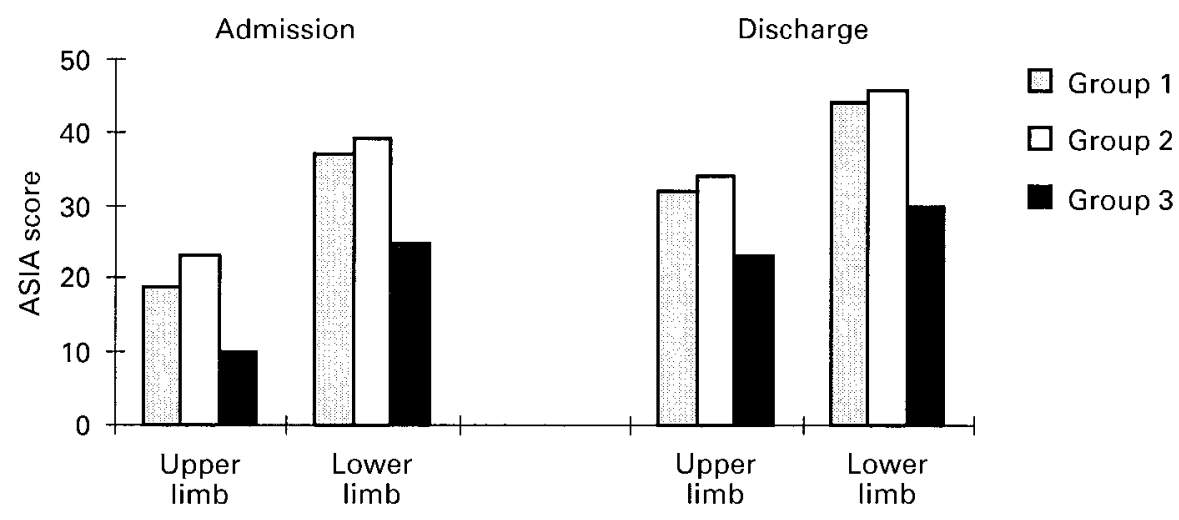

Fig. 1

Mean ASIA scores at admission and discharge for the three groups. 


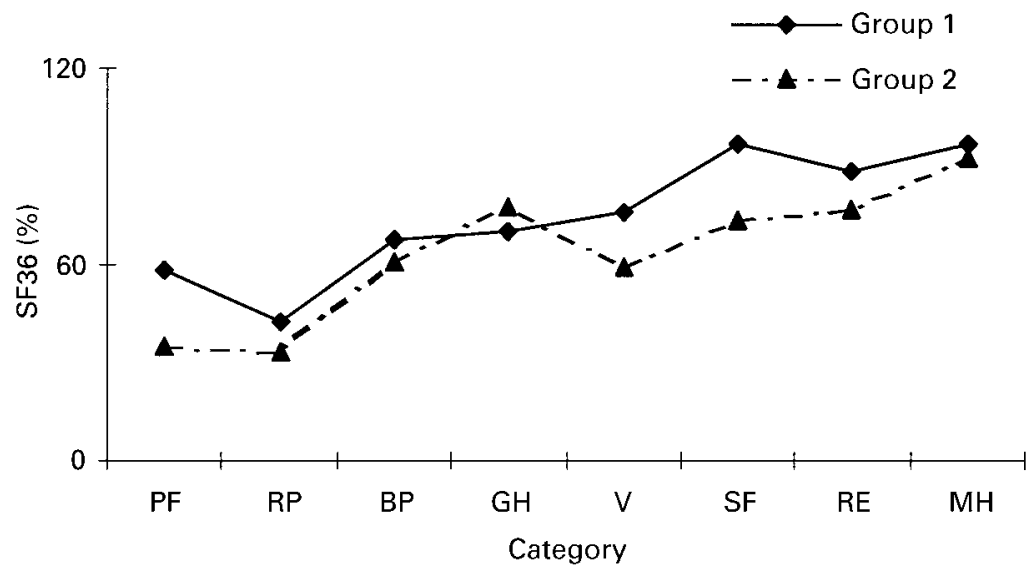

Fig. 2

SF36 Health Profiles standardised for age and gender for groups 1 and 2 .

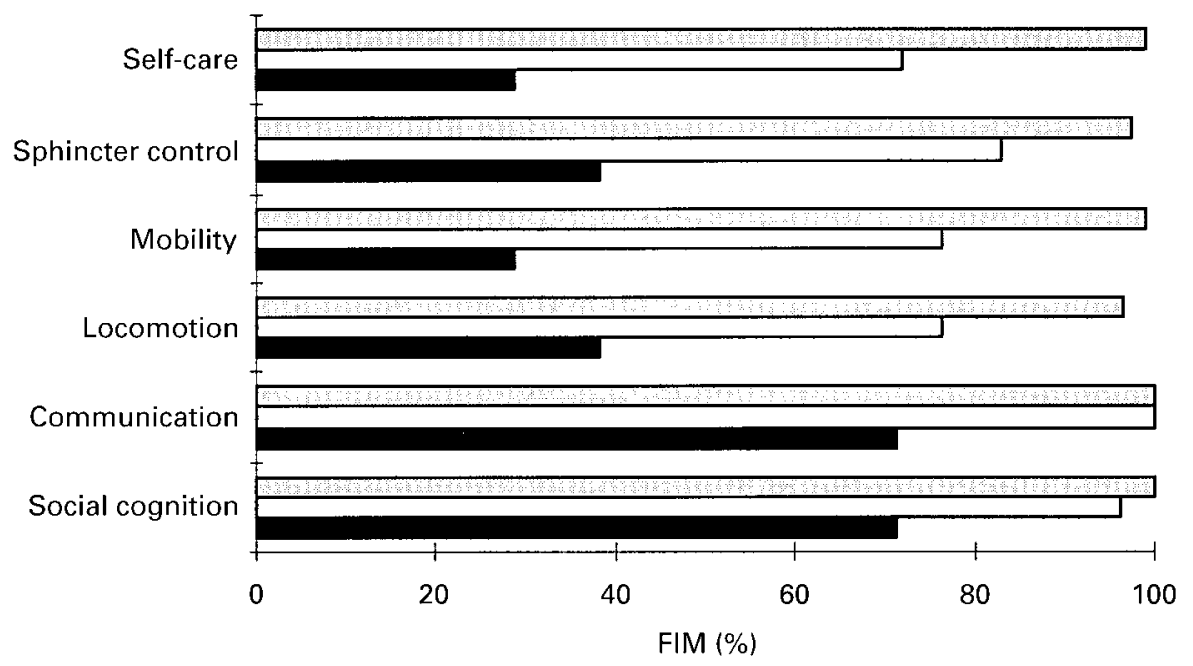

Group 1

$\square$ Group 2

Group 3

Fig. 3

Functional Independence Measure (FIM) for the three groups at review.

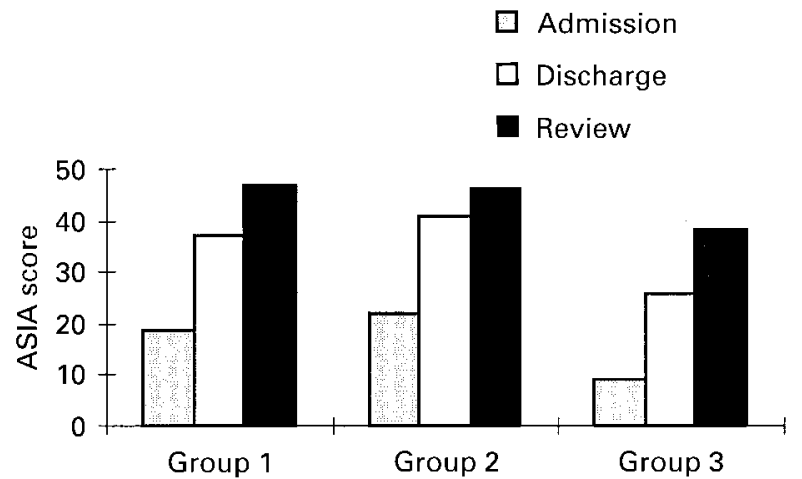

Fig. $4 \mathrm{a}$

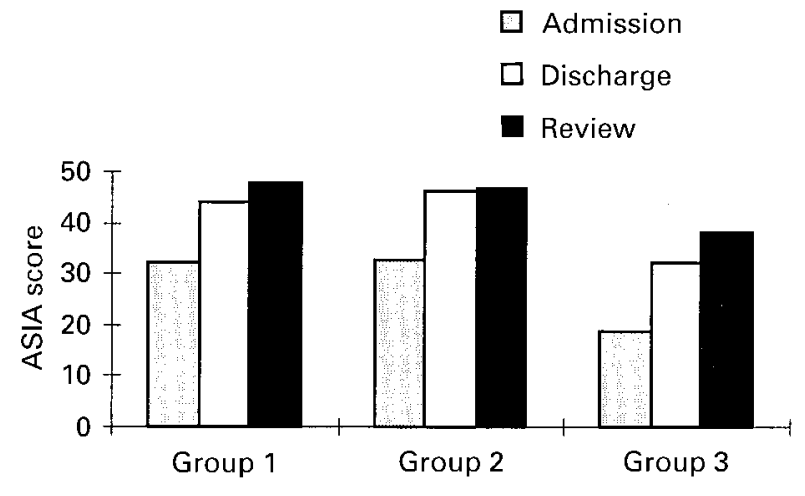

Fig. 4b

Mean ASIA scores for a) upper and b) lower limbs from admission to review.

power was normal. Spasticity was not a feature although most patients had brisk reflexes and ten continued to experience spasms.

Five patients in group 1 and six in group 2 described altered sensation, ranging from minor reduction in light touch to absence of sensation of pain or temperature. The distribution of sensory impairment did not fit any recognisable pattern.
Four patients in group 1 had returned to work although two were subsequently granted an invalidity pension. Two patients in group 2 continue to work part-time. The remainder were retired.

At the final review all patients in group 1 were living at home, compared with ten $(77 \%)$ of group 2 and only one of group 3. Since discharge one patient each from groups 2 and 3 has been placed in long-term care. 

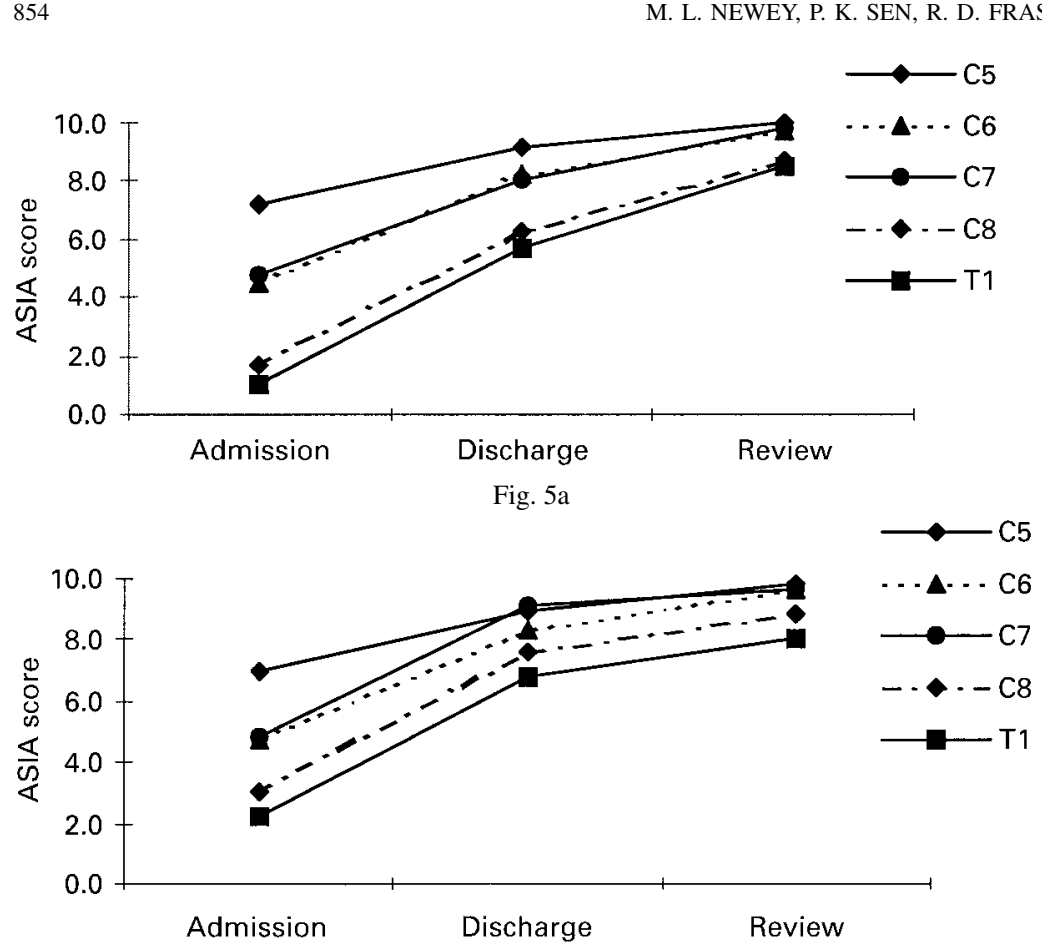

Fig. $5 b$

All deaths occurred in groups 2 and 3 and the time interval to death was compared for each patient with their life expectancy as obtained from the Australian Bureau of Statistics. ${ }^{12}$ Five patients had died within two years of injury (Fig. 6) and all lived less than $20 \%$ of their life expectancy from the time of injury (Fig. 7). They were all in group 3.

Patients who lived for more than two years after injury

Table IV. Comparison of patients who died within two years of injury with those who lived for more than two years

\begin{tabular}{lll}
\hline & $\begin{array}{c}\text { Died <2 years } \\
\text { from injury }\end{array}$ & $\begin{array}{l}\text { Died >2 years } \\
\text { from injury }\end{array}$ \\
\hline Mean age at injury in years & 79 & 68 \\
Walking (at discharge) & $1 / 5$ & $3 / 5$ \\
Walking (before death) & $1 / 5$ & $4 / 5$ \\
Bladder control (at discharge) & 0 & $4 / 5$ \\
Bladder control (before death) & 0 & $4 / 5$ \\
Living at home (before death) & 0 & $3 / 5$ \\
\hline
\end{tabular}

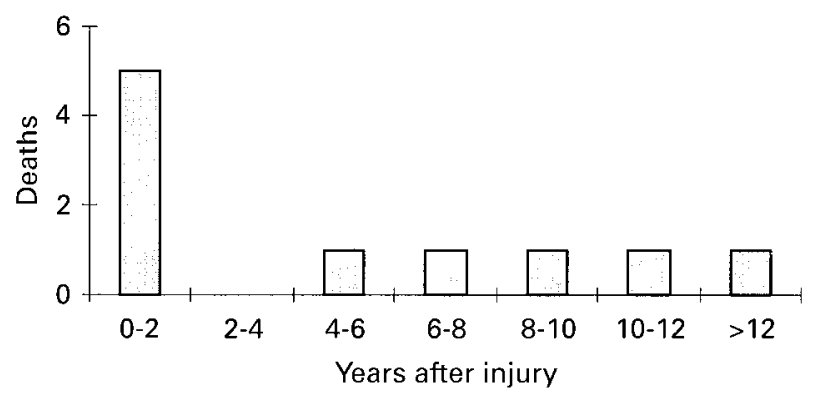

Fig. 6

Time of death after injury in ten patients.
Improvement in ASIA scores for upper limb roots from admission to review for a) group 1 and b) group 2 . were younger and had achieved good function by the time of discharge from rehabilitation; this appeared to have been maintained up to the time of death. By contrast, those who died within two years of injury were older and had not achieved good function either at discharge or at the time of death (Table IV).

\section{Discussion}

The classic paper on central cord syndrome by Schneider et $\mathrm{al}^{1}$ was based on a group of patients between 18 and 85 years of age. Hyperextension of a degenerative cervical spine was the predominant mechanism of injury, and recovery followed a set pattern beginning with the lower limbs and ending with hand function. The authors stated that surgery was contraindicated and this set a trend with subsequent authors reporting the outcome after conservative management.

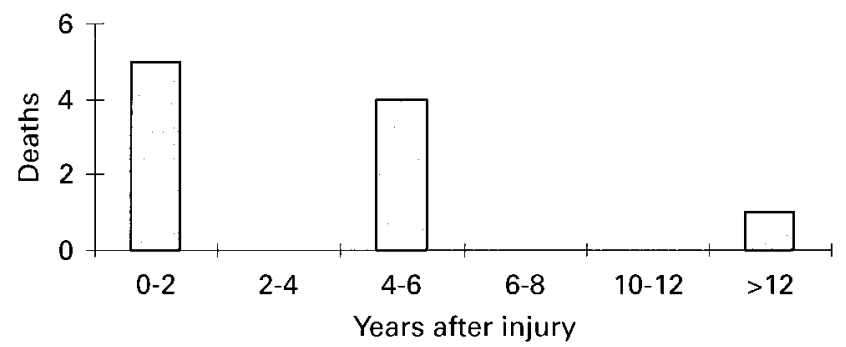

Fig. 7

Survival expressed as percentage of life expectancy from injury. 
Bosch et $\mathrm{al}^{2}$ reviewed 42 patients in whom walking and hand, bowel and bladder function had returned in $50 \%$ to $60 \%$, but the precise time of follow-up for this group was unclear. Shrosbree ${ }^{3}$ reported 99 patients in $80 \%$ of whom walking and hand function recovered, but not all patients had central cord syndrome and less than a third were over 50 years of age. Merriam et $\mathrm{al}^{4}$ reported 77 patients of whom $73 \%$ were independent and $65 \%$ had good bladder function at six months. The mean age was 34.6 years and 30 had been treated surgically. Roth et $\mathrm{al}^{5}$ reviewed 81 patients six months after discharge and found that $70 \%$ were independent and $84 \%$ had bladder control. Their mean age was 45 years and about half had undergone surgery.

Penrod et al ${ }^{10}$ reported a favourable prognosis in patients under 50 years of age but the method of treatment was not described. Some authors ${ }^{7-9}$ have suggested that surgery is indicated in selected cases, but none of these studies was prospective or randomised.

In our study, all the patients had been treated conservatively unless there was a major fracture or dislocation or extrinsic compression of the cord at presentation.

All patients over 50 years of age had gross degenerative changes of the cervical spine whereas only three $(50 \%)$ of those under 50 had such changes.

Fractures occurring in patients under 50 years of age resulted from compression injuries to the anterior column whereas those in patients over 50 years of age involved the posterior elements, consistent with hyperextension. Fracture was uncommon in patients over 70 years of age. There would therefore appear to be differing age-related patterns of injury which are associated with differences in neurological deficit. The latter is more severe in patients over 70 years of age.

We also noted age-related differences in outcome, although these were not as marked as previously described. ${ }^{5,10}$ We found that patients under 50 years of age had satisfactory return of motor and bladder function, although this improvement was not matched by ability to work. Furthermore, our study suggests that the poorer outcome previously observed in patients over 50 years of age is heavily weighted by a particularly bad outcome in those over 70 years of age.

Contrary to the findings of Bosch et al, $^{2}$ spasticity does not appear to cause significant functional problems. Motor power continued to improve after discharge. The more distal roots of the upper limb were more affected causing some compromise of the fine motor control of the hand in $38 \%$ of patients in group 2 and in all of group 3. Fatigue was common to all age groups, as has been previously reported. $^{6}$

Our study is limited in that it is retrospective and based on small numbers. Nevertheless, it provides an indication of the natural history of patients presenting with central cord syndrome, and although the results are encouraging, particularly for patients between 50 and 70 years of age whose outcome had previously been thought to be poor, the question still remains as to whether, and under what circumstances, decompressive surgery may improve the outcome.

No benefits in any form have been received or will be received from a commercial party related directly or indirectly to the subject of this article.

\section{References}

1. Schneider RC, Cherry G, Pantek H. The syndrome of acute central cervical spinal cord injury: with special reference to the mechanisms involved in hyperextension injuries of the cervical spine. J Neurosurg 1954;11:546-77.

2. Bosch A, Stauffer ES, Nickel VL. Incomplete traumatic quadriplegia: a ten year review. JAMA 1971;216:473-8.

3. Shrosbree RD. Acute central cervical spinal cord syndrome: aetiology, age incidence and relationship to the orthopaedic injury. Paraplegia 1977; 14:251-8.

4. Merriam WF, Taylor TKF, Ruff SJ, McPhail MJ. A reappraisal of acute traumatic central cord syndrome. J Bone Joint Surg $[\mathrm{Br}]$ 1986;68-B:708-13.

5. Roth EJ, Lawler MH, Yarkony GM. Traumatic central cord syndrome: clinical features and functional outcomes. Arch Phys Med Rehabil 1990;71:18-23.

6. Bridle MJ, Lynch KB, Quesenberry CM. Long term function following the central cord syndrome. Paraplegia 1990;28:178-85.

7. Brodkey JS, Miller CF, Harmody RM. The syndrome of acute central cervical spinal cord injury revisited. Surg Neurol 1980;14:247-51.

8. Bose B, Northrup BE, Osterholm JL, Cotler JM, Ditunno JF. Reanalysis of central cervical cord injury management. Neurosurgery 1984;15:367-72.

9. Chen TY, Lee ST, Lui TN, et al. Efficacy of surgical treatment in traumatic central cord syndrome. Surg Neurol 1997;48:435-41.

10. Penrod LE, Hegde SK, Ditunno JF. Age effect on prognosis for functional recovery in acute, traumatic central cord syndrome. Arch Phys Med Rehabil 1990;71:963-8.

11. ABS National Health Survey 1995. SF36 Population Norms, Australia, ABS catalogue no. 4399.0.

12. ABS publication 1996: Deaths, Australia, ABS catalogue no. 3302.0 . 